$\mathbb{P}$ periodica polytechnica

Civil Engineering

$56 / 2(2012) 127,140$

doi: 10.3311/pp.ci.2012-2.01

web: http://www.pp.bme.hu/ci

(c) Periodica Polytechnica 2012

RESEARCH ARTICLE

\section{On the 2D modelling aspects of wind-induced waves in shallow, fetch-limited lakes}

\author{
Krisztián Homoródi / János Józsa / Tamás Krámer
}

Received 2011-07-02, revised 2011-08-30, accepted 2012-02-24

\begin{abstract}
Wind-induced waves play an important role in shallow lake hydro- and sediment dynamics. But most of the field measurement methods can give information about the wave properties only at single point, which calls for wave estimation methods to take the effect of waves into account in multidimensional hydroand sediment dynamic models. The aim of this study is to improve modelling waves in depth- and fetch-limited lakes generated by the local winds.

In the first part of this paper, we describe the calibration and validation of the 2D spectral wave model SWAN (Simulating Waves Nearshore) to the very shallow Lake Neusiedl, Hungary/Austria.

The abrupt change of the roughness at the perimeter of the open lake and the gradual change along the fetch due to wave growth result in a systematic, fetch-dependent variation of the wind speed. This spatial inhomogeneity is modelled here by a ID atmospheric internal boundary layer (IBL) model. It is shown in the second part of this paper that this approach results in a significant effect on wave parameters and, as a consequence, on bottom shear stress.
\end{abstract}

\section{Keywords}

$2 D$ numerical wave model SWAN · Shore Protection Manual $(S P M) \cdot$ shallow lake $\cdot$ internal boundary layer

\section{Krisztián Homoródi}

Budapest University of Technology and Economics, Department of Hydraulic and Water Resources Engineering, H-1111 Budapest, Múegyetem rkp. 3. Kmf. 12 , Hungary

e-mail: homorodi@vit.bme.hu

\section{János Józsa}

Budapest University of Technology and Economics, Department of Hydraulic and Water Resources Engineering also MTA-BME Water Management Research Group, H-1111 Budapest, Múegyetem rkp. 3. Kmf. 12, Hungary

\section{Tamás Krámer}

Budapest University of Technology and Economics, Department of Hydraulic and Water Resources Engineering, H-1111 Budapest, Múegyetem rkp. 3. Kmf. 12, Hungary

\section{Introduction}

Wind-induced surface waves and the consequent periodic motion of the water column are known to play an important role in shallow lakes hydro- and sediment dynamics, e.g. in bed material stirring-up or wave loading on beach protection works. Field measurements and their detailed analysis are still essential to obtain a more realistic insight into wave features in shallow conditions. However, most of the field measurement methods can give information about the wave properties only at single point, which is usually not enough for spatial characterisation. For the spatial extension of the description of the hydrodynamic state (including the wave field) a choice is to apply some analytical/empirical estimation formulae or numerical models. In fact, numerical models are widely used to investigate the hydrodynamic processes in lakes (see e.g. [25], and even in such complex conditions as river confluences [3]. By means of wave estimation formulas or numerical models it becomes then, possible to extend our knowledge also about the wave properties to the whole investigated lake. Before using any estimation method it must be checked that it can reproduce the measured wave data sufficiently well. As to semi-analytical approaches, the Shore Protection Manual (SPM) contains widely used formulas for the estimation of significant wave height and average wave period in shallow water (CERC, 1984). In spite of their simplicity these formulas showed decent agreement with measurements e.g. in Lake Balaton [28].As to numerical modelling tools, we will focus on SWAN (standing for Simulating Waves Nearshore) which is a $2 \mathrm{D}$ spectral wave model developed for the simulation of wind generated waves from the nearshore to the surf-zone [5]. and [33].

The aim of this study is to improve modelling waves in shallow, fetch-limited lakes generated by the local winds.

In the first part the implementation, calibration and validation of the SWAN model for Lake Neusiedl is described. Model results are compared with not just measured data but also with the results obtained by the SPM formulas.

In a typical lake environment, surface properties change abruptly as the wind transits land, emerging vegetation and open water. The abrupt variation of the roughness at the land-water 
and reed-water interfaces results in an inhomogeneous, fetchdependent wind speed distribution over the lake even in steadystate conditions. In such conditions, the spatial inhomogeneity of the wind speed can be modelled by an atmospheric internal boundary layer (IBL) model [21]. In the second part of this paper it is shown that this inhomogeneity of the wind field has significant effect on wave properties. In shallow lakes the shear stress on the lake bottom, which is mainly caused by the surface waves, plays a determining role in sediment dynamics, as a consequence the variability of the wind field is transferred into the distribution of the bottom shear stress.

\section{Study area and field data}

A particular feature of Lake Neusiedl is its huge littoral reed belt (indicated in gray in Fig. 1), with large reed patches also also away from the belt. Though the water exchange, siltation and wave attenuation processes are very important in the reed zones, the first investigations focused on the off shore areas where it is simpler to deploy hydrometric instruments. In the lake two wave measurement campaigns longer than one week were conducted near Illmitz, Austria in 2005.

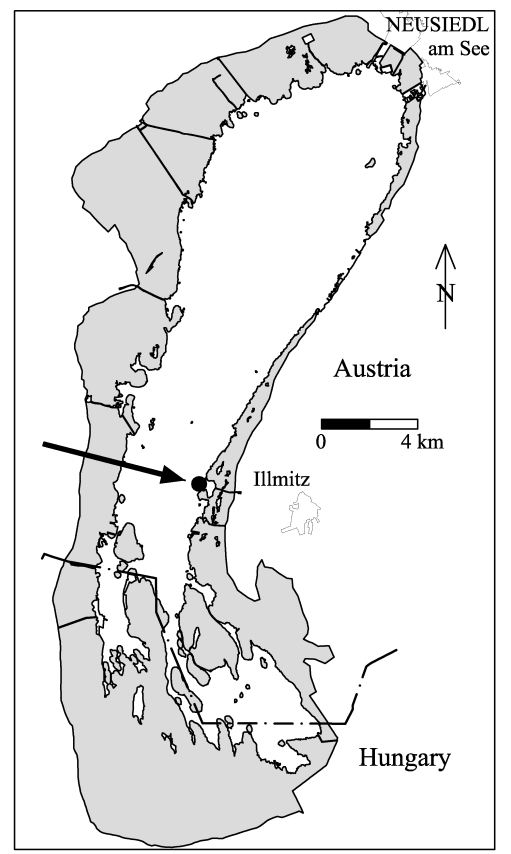

Fig. 1. Measurement location near Illmitz, in Lake Neusiedl shown with a thick arrow

In these campaigns a standard wave pressure gauge was used placed directly on the lake bottom thanks to a custom-made rack. The depth of the lake at the measurement site was as small as $1.0-1.1 \mathrm{~m}$, thus the sensor head was $0.60 \mathrm{~m}$ below the mean water surface. Wave data were collected using 5-min bursts with $8 \mathrm{~Hz}$ sampling rate, triggered every $30 \mathrm{~min}$ (Figs. 3 and 4 . Based on the linear wave theory the wave spectra were reconstructed from the measured pressure data and two wave parame- ters were derived from moments of these spectra (WMO, 1998):

$$
\begin{aligned}
H_{\mathrm{m} 0} & =4 \sqrt{m_{0}} \\
T_{\mathrm{m} 01} & =m_{0} / m_{1}
\end{aligned}
$$

with $H_{m 0}=$ significant wave height; $T_{m 01}=$ wave period corresponding to the mean frequency of the spectrum; $m_{0}$ and $m_{1}=$ zero-order and first-order moments of the wave spectrum.

Besides water pressure, wind speed and direction were also measured at the same location at 3.3-3.5 m above the surface at half-a-minute sampling interval (Fig. 3 and 4 ). The measurement location was chosen to provide more than $4-5 \mathrm{~km}$ fetches for the prevailing N-NW wind directions.

As is known, the standard wind measurement height is at $10 \mathrm{~m}$ above the surface. Wave estimation formulas and also the applied 2D numerical wave model expect wind speed at this location as input data. The wind friction velocity, which characterises in the energy transfer processes between the wind and the waves, can be calculated with the following equation:

$$
w_{*}^{2}=C_{D} w_{10}^{2},
$$

with $w_{*}=$ wind friction velocity; $w_{10}=$ wind speed at $10 \mathrm{~m}$ height; $C_{D}=$ drag coefficient, which we specify $C_{D}$ according to $\mathrm{Wu}$ (1982). In a neutral atmospheric surface layer, the horizontal wind speed is traditionally expressed as a logarithmic function of height:

$$
w_{z}=\frac{w_{*}}{\kappa} \ln \frac{z}{z_{0}},
$$

with $w_{z}=$ horizontal wind speed at height $z$ above the surface; $\kappa \approx 0.4=$ von Kármán's constant; $z_{0}=$ surface roughness length. In a typical lake environment, surface properties change abruptly on the way blowing across land, emerging vegetation and open water. This abrupt variation has an immediate effect on the air flow near the surface, and the disturbance then propagates upwards on the leeside with turbulent diffusion, giving rise to an internal boundary layer. Besides the abrupt variation of $z_{0}$ at the land-reed-water interfaces, $z_{0}$ also varies smoothly over the open lake due to the variable waviness of the water surface. The above mentioned spatial inhomogeneity of $w_{z}$ and $w_{*}$ is modelled by an atmospheric internal boundary layer (IBL) model, which results in a fetch-dependent wind velocity and friction velocity distribution over the lake even in uniform overland wind conditions. Based on this model wind speed can be transformed within the surface layer for example from the shore to the open water or the other way around, and between two heights at any point. The validity of this estimation method was proved with field measurements in Lake Neusiedl [21]. In our applications, the measured wind data were transformed from the measurement height (3.3-3.5 m) to $10 \mathrm{~m}$, the standard anemometer height. In the remaining part of this paper $w$ will indicate wind speed at 10 $\mathrm{m}$ above the surface.

The most important difference between the two measurement periods in July and October was the direction of the strongest 


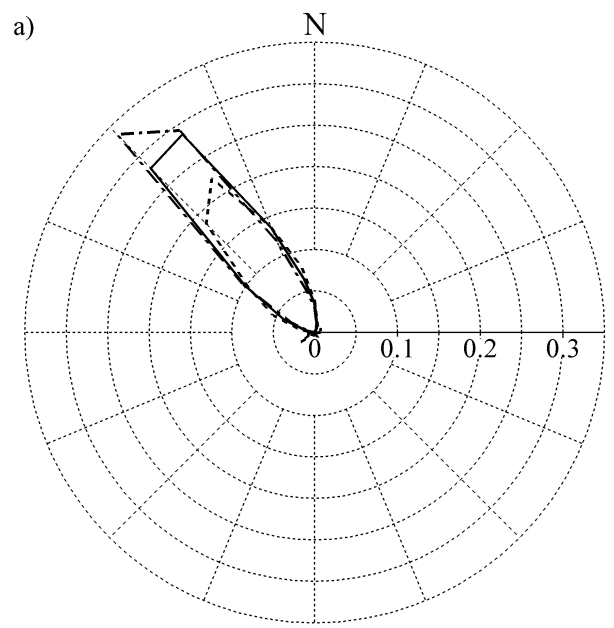

Fig. 2. Wind direction (dashed line), energy (solid line) and power (dashdotted line) diagrams for the two measurement campaigns in July (a) and Octo-

winds: it was NW during the first period in July and $\mathrm{N}$ during the second period in October (Fig. $2 a$ and $b$ ). This difference is favourable as it allows a validation to various wind exposures.

\section{Wave estimation formulas of the Shore Protection Manual (SPM)}

In this approach we use formulas for the estimation of significant wave height and average wave period using only the local wind speed, fetch and water depth as input data, usually all available. An advantage is that a huge computational effort is not needed compared to the 2D numerical model. The formulas for the significant wave height and average wave period given by the Shore Protection Manual (CERC, 1984) are as follows:

$$
\begin{aligned}
H_{\mathrm{s}}= & 0.283 \frac{w^{2}}{g} \tanh \left(0.530\left(\frac{g h}{w^{2}}\right)^{0.75}\right) \\
& \times \tanh \left[\frac{0.00565\left(\frac{g F}{w^{2}}\right)^{0.5}}{\tanh \left(0.530\left(\frac{g h}{w^{2}}\right)^{0.75}\right)}\right], \\
T_{\mathrm{a}}= & 7.54 \frac{w}{g} \tanh \left(0.833\left(\frac{g h}{w^{2}}\right)^{0.375}\right) \\
& \times \tanh \left[\frac{0.0379\left(\frac{g F}{w^{2}}\right)^{0.333}}{\tanh \left(0.833\left(\frac{g h}{w^{2}}\right)^{0.375}\right)}\right],
\end{aligned}
$$

with $H_{s}=$ significant wave height; $T_{a}=$ average wave period; $w=$ wind speed; $h=$ local water depth; $F=$ fetch; $g=$ acceleration due to gravity. As their validation in shallow lakes, these formulas were used in Lake Balaton with reasonable agreement with measurements (Krámer and Peltoniemi, 2006). Thanks to its complexity we expect the SWAN model to represent the temporal dynamics significantly more accurately than a steadystate regression method, so we compare the modelled bulk wave properties not only to the measured data but also to the estimation by the SPM formulas (Fig. 3 and 4 ). This procedure is described in chapter 6 .

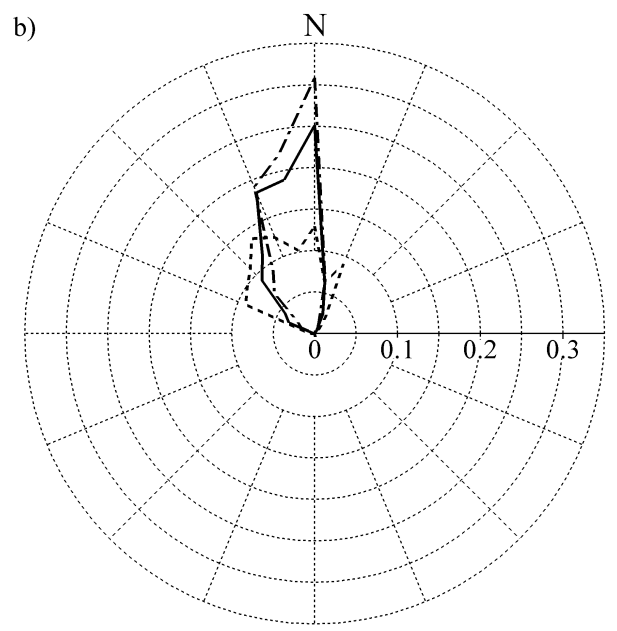

ber (b) 2005

\section{The SWAN model}

The SWAN model (version 40.81, [5] and [33]) is a so-called third generation spectral wave model. It was developed for the simulation of wind generated waves from the nearshore to the surf-zone, but it was also used in deep lakes like Lake Erie (Moeini and Etemad-Shahidi, 2009) and shallow lakes like Lake Okeechobee [20] or shallow bays like the Chesapeake Bay [27] and the Kündema Bay [1] this model, focusing on the processes with high relevance in shallow water conditions typical to Lake Neusiedl based on its scientific and technical documentation (SWAN team, 2010).

Because the irregular nature of wind causes irregularity in the wave heights and periods, instead of a deterministic approach the variance or the energy density spectrum can be used to describe the sea state. To be precise, the energy density is not conserved in the presence of currents, so SWAN considers the action density rather than the energy density. The relation between the two is written as

$$
N(f, \theta)=E(f, \theta) / f
$$

where $N(f, \theta)$ and $E(f, \theta)=$ action density and energy density of the wave component with $f$ relative frequency (as observed in a frame of reference moving with current velocity), and $\theta$ wave direction (the direction normal to the wave crest of each spectral component). In the SWAN wave model, the evolution of the wave spectrum at position $(x, y)$ and time $(t)$ is described by the spectral action balance equation, which for Cartesian coordinates is

$$
\frac{\partial N}{\partial t}+\frac{\partial c_{x} N}{\partial x}+\frac{\partial c_{y} N}{\partial y}+\frac{\partial c_{f} N}{\partial f}+\frac{\partial c_{\theta} N}{\partial \theta}=\frac{S}{f}
$$

with $c_{x}$ and $c_{y}=$ propagation speed in geographical space; $c_{f}$ and $c_{\theta}=$ propagation speed in spectral space. The first term in the left-hand side of this equation represents the local rate of change of action density in time. The other four terms on that side represent propagation of action density in geographical and spectral space. Shifting of the relative frequency due 

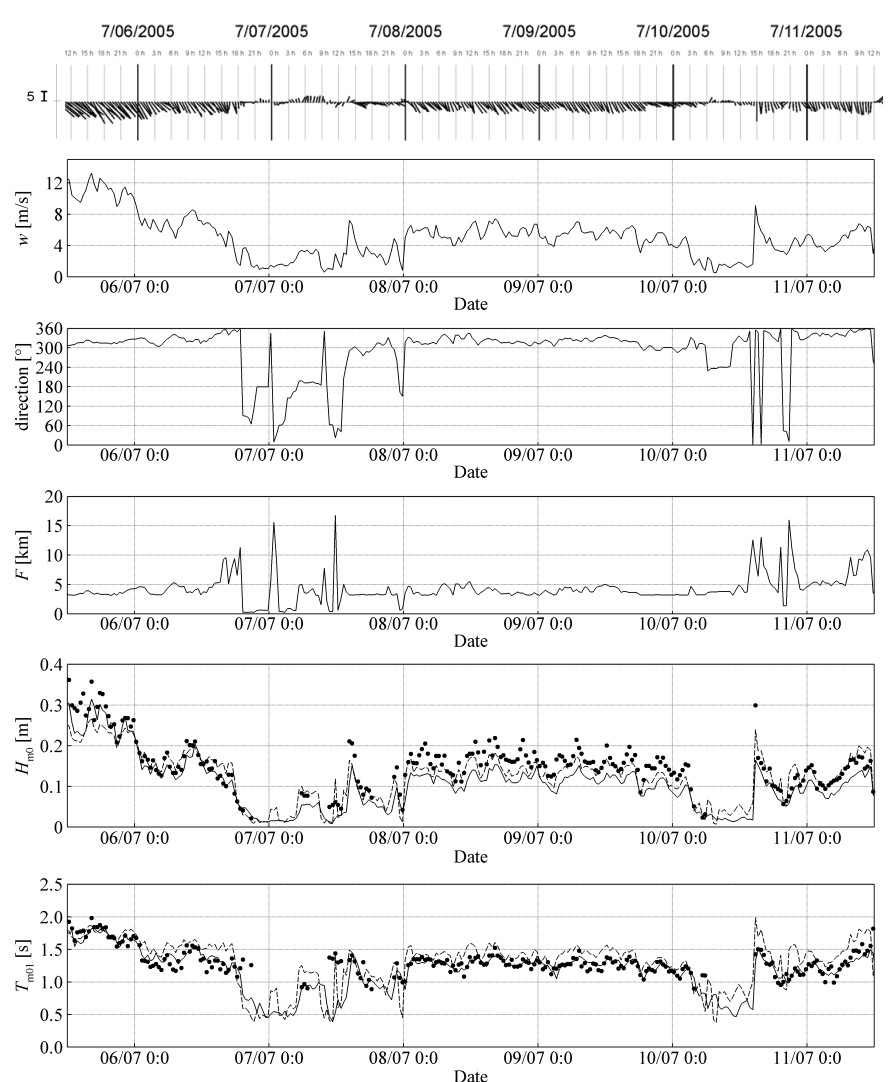

Fig. 3. From top to bottom: Measured wind data (wind stick plot, wind speed and direction), fetch, measured (dots) and estimated $H_{m 0}$ and $T_{m 01}$ (SPM

dashed line, SWAN solid line) for a 6-day-long characteristic interval of the campaign in July 2005
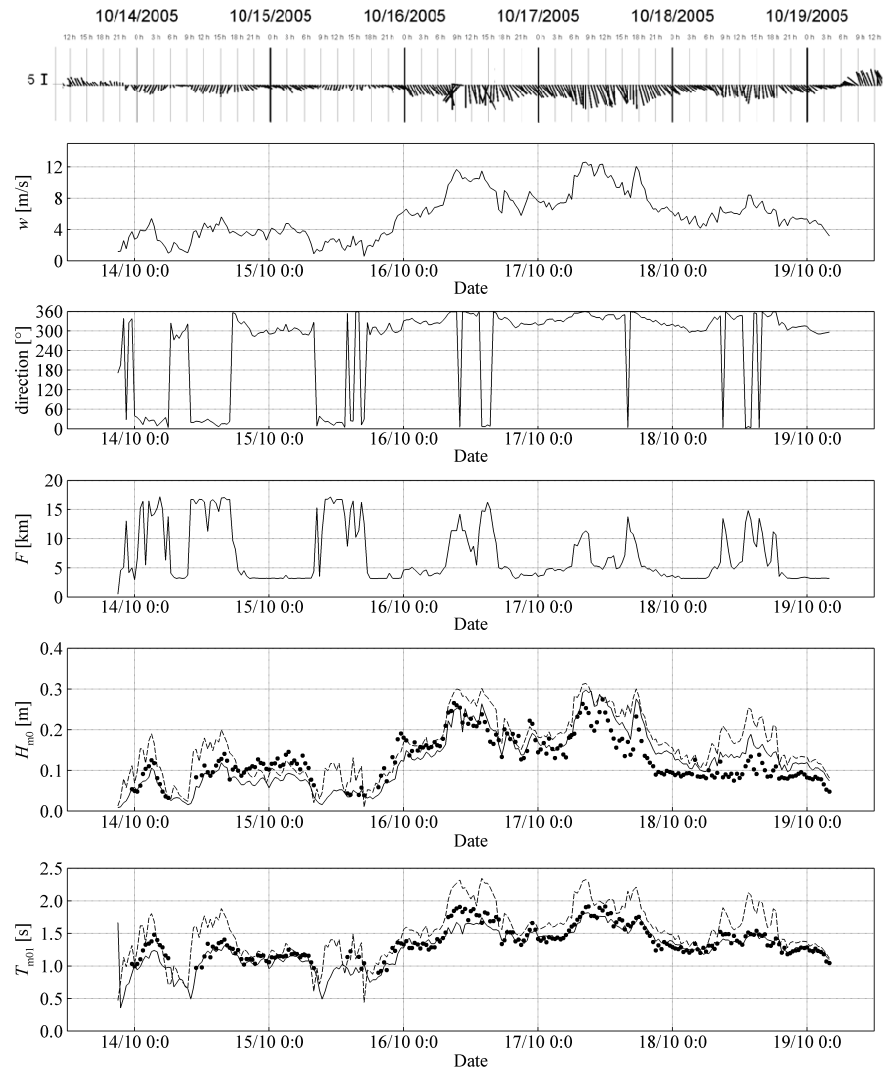

Fig. 4. Same as Fig. 3 for the data observed in October 2005

to variations in depths and currents, depth-induced and current- tional spreading are represented by the fourth and fifth term. induced refraction, propagation in directional space and direc- The term $S=S(f, \theta)$ on the right hand side of the action balance 
equation is the sum of source terms representing the linear and exponential growth by wind, dissipation due to whitecapping and bottom friction, depth-induced wave breaking and energy transfer due to quadruplet and triad wave-wave interaction.

Transfer of wind energy to the waves is described in SWAN with the resonance mechanism of Phillips (1957) and the feedback mechanism of Miles (1957). The source term for these mechanisms is a combination of linear and exponential terms as follows:

$$
S_{\text {in }}(f, \theta)=A+B E(f, \theta) .
$$

The expression for $B$,

$$
B=\beta \frac{\rho_{\mathrm{a}}}{\rho_{\mathrm{w}}}\left(\frac{w_{*}}{c_{\mathrm{ph}}}\right)^{2} \max \left[0, \cos \left(\theta-\theta_{\mathrm{w}}\right)\right]^{2} f,
$$

is due to Janssen (1991) and it accounts explicitly for the interaction between wind and waves by considering atmospheric boundary layer effects and the roughness length of the water surface. The new variables are $\beta=$ Miles constant; $\rho_{a}$ and $\rho_{w}=$ density of air and water, respectively; $c_{p h}=$ wave phase speed; $\theta_{w}=$ the wind direction. This option is similar to the one in WAM Cycle 4 [23] The expression for linear growth term $A$, as described by [6], is also included to initiate wave action from a zero-energy state, but it is negligible except at the beginning of the wave generation.

The whitecapping source term is derived from the model of Hasselmann (1974), which considers whitecaps as randomly distributed pressure pulses:

$$
S_{d s, w}(f, \theta)=-\Gamma \tilde{f} \frac{k}{\tilde{k}} E(f, \theta),
$$

with $\tilde{f}$ and $\tilde{k}=$ mean frequency and wave number; $\Gamma=$ a coefficient that depends on the overall wave steepness $\tilde{s}$. This steepness-dependent coefficient, as given by WAMDI group (1988), was adapted by Günter et al. (1992) based on Janssen (1991):

$$
\Gamma=C_{\mathrm{ds}}\left((1-\delta)+\delta \frac{k}{\tilde{k}}\right)\left(\frac{\tilde{s}}{\tilde{s}_{P M}}\right)^{p},
$$

with $C_{d s}, \delta$ and $p=$ tuneable parameters, $\tilde{s}=$ the overall wave steepness, $\tilde{s}_{P M}=$ the value of $\tilde{s}$ for the Pierson-Moskowitz spectrum (1964): $\tilde{s}_{P M}=\sqrt{3.02 \times 10^{-3}}$. The default values of the tuneable parameters are $C_{d s}=4.1 \times 10^{-5}, \delta=0.5$ and $p=4$. In the input file describing the parameters of the simulation for the model $C_{\mathrm{ds}}^{\prime}=C_{\mathrm{ds}} / \tilde{s}_{P M}$ is given instead of $C_{d s}$, with a default value of 4.5. Composite scaled sensitivities (Hill, 1998) show that $H_{m 0}$ and $T_{m 01}$ are sensitive to $C_{\mathrm{ds}}^{\prime}$ and $\delta$ but not to $p$ (Ta-

\begin{tabular}{|c|c|c|c|c|}
\hline & $C_{\mathrm{ds}}^{\prime}$ & $\delta$ & $p$ & $k_{n}$ \\
\hline$H_{m 0}$ & 0.059 & 0.017 & 0.001 & 0.006 \\
\hline$\overline{T_{m 01}}$ & 0.084 & 0.123 & 0.020 & 0.022 \\
\hline
\end{tabular}
ble 1 .

Tab. 1. Composite scaled sensitivity of $H_{m 0}$ and $T_{m 01}$ to parameters $C_{\mathrm{ds}}^{\prime}, \delta$, $p$ and $k_{n}$
Higher $C_{\mathrm{ds}}^{\prime}$ values increase energy dissipation, reducing $H_{m 0}$ and (less strongly) $T_{m 01}$ as a result (Fig. 5). The effect is more pronounced above $H_{m 0}=0.15 \mathrm{~m}$. The bulk parameters $H_{m 0}$ and $T_{m 01}$ are also found sensitive to an increase, but less to a reduction of $\delta$ (Fig. 6). Perturbing $\delta$ changes $H_{m 0}$ with the opposite sign and $T_{m 01}$ with the same sign.

The process of wave energy dissipation at the lakebed can be estimated based on the empirical JONSWAP form [16], the drag law model of Collins (1972) [8] or the eddy-viscosity model of Madsen et al. (1988) [28]. All the three methods use the following equation:

$$
S_{d s, b}(f, \theta)=-C_{b} \frac{f^{2}}{g^{2} \sinh ^{2} k h} E(f, \theta),
$$

with $C_{b}=$ bottom friction coefficient; $h=$ water depth. The difference is in the estimation of the $C_{b}$ bottom friction coefficient. In the model by Madsen et al. the bottom friction coefficient depends on the bottom roughness height $k_{n}$ and the actual wave conditions. $H_{m 0}$ and $T_{m 01}$ are sensitive to $k_{n}$ only at higher waves because for lower waves there is at most a weak or no interaction between the waves and the lake bottom (Fig. 7).

The shape and evolution of a wind wave spectrum are largely controlled by nonlinear interactions, which transfer energy between frequency ranges. In deep water, quadruplet wave-wave interactions dominate the evolution of the spectrum. They transfer wave energy from the spectral peak to lower frequencies (thus moving the peak frequency to lower values) and to higher frequencies (where the energy is dissipated by whitecapping). Computing this term for typical model applications is conducted by a discrete interaction approximation [16] for the four-wave interaction within the SWAN model.

In very shallow waters, triad wave-wave interactions transfer energy from lower frequencies to higher frequencies, often resulting in higher harmonics. A parameterization of this effect is included in SWAN using the lumped triad approximation [11]. The triad term becomes significant only for depths which are very small relative to wave height and wave length.

When waves propagate towards the shore, shoaling leads to an increase in wave height. When the ratio of wave height over water depth exceeds a certain limit, waves start to break. The energy dissipation due to the depth-induced breaking is treated by the Eldeberky and Battjes (1996) spectral formulation for random waves and is based on the bore model of Battjes and Janssen (1978). It has a significant effect on wave properties only nearshore.

The action balance equation (8) is solved in SWAN with the finite difference method. A rectangular computational grid was used in our investigation with constant cell size $\Delta x$ and $\Delta y$ in the $x$ - and $y$-direction, respectively. The spectral space is divided into elementary bins with a constant directional resolution $\Delta \theta$ and a constant relative frequency resolution $\Delta f / f$ (resulting in a logarithmic frequency distribution). Details about the numerical approaches are given in the SWAN user manual (SWAN team, 

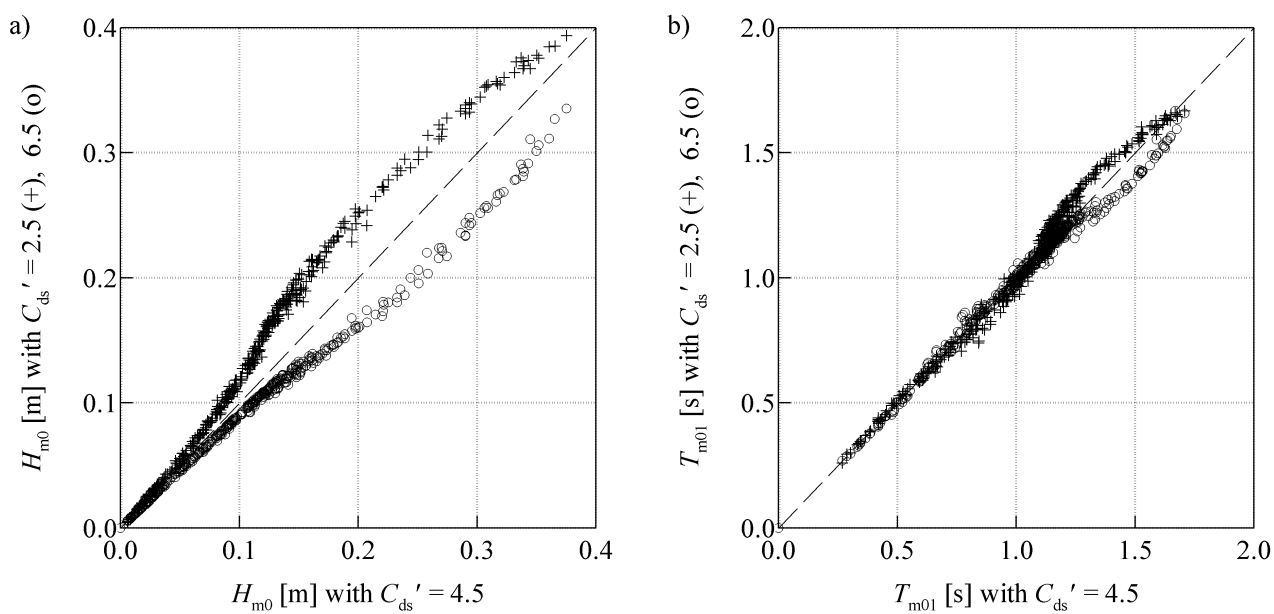

Fig. 5. Scatter diagram of $H_{m 0}$ (a) and $T_{m 01}$ (b) for different $C_{\mathrm{ds}}^{\prime}$ values. The dashed diagonal represents an exact match, i.e. no sensitivity
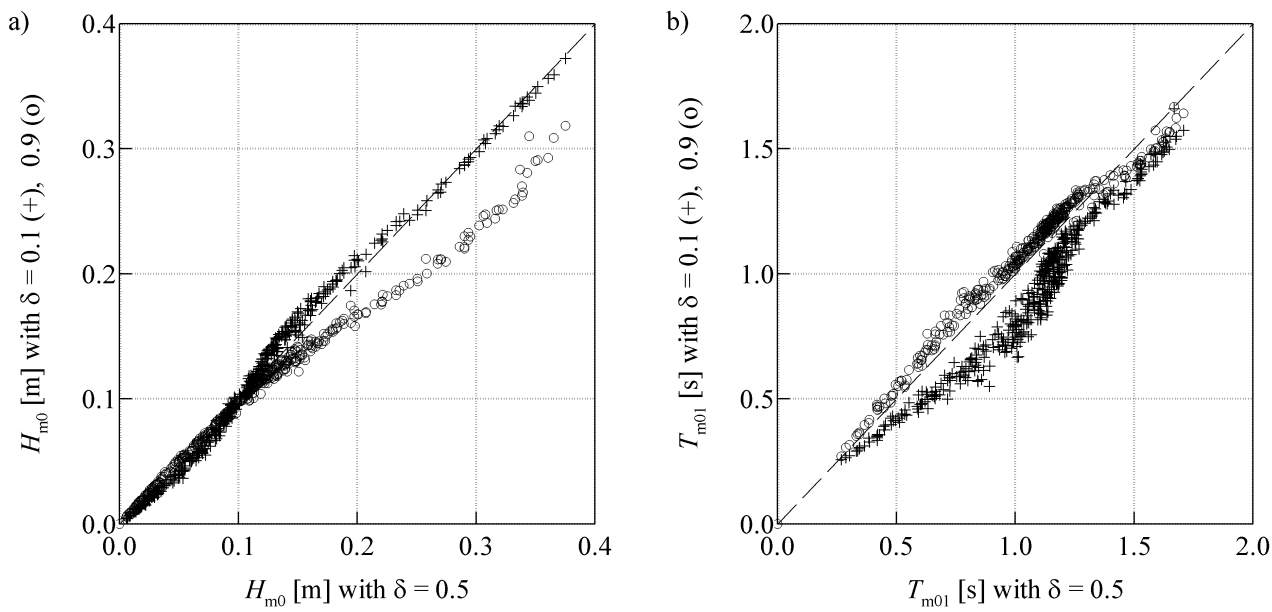

Fig. 6. Scatter diagram of $H_{m 0}$ (a) and $T_{m 01}$ (b) for different $\delta$ values. The dashed diagonal represents an exact match
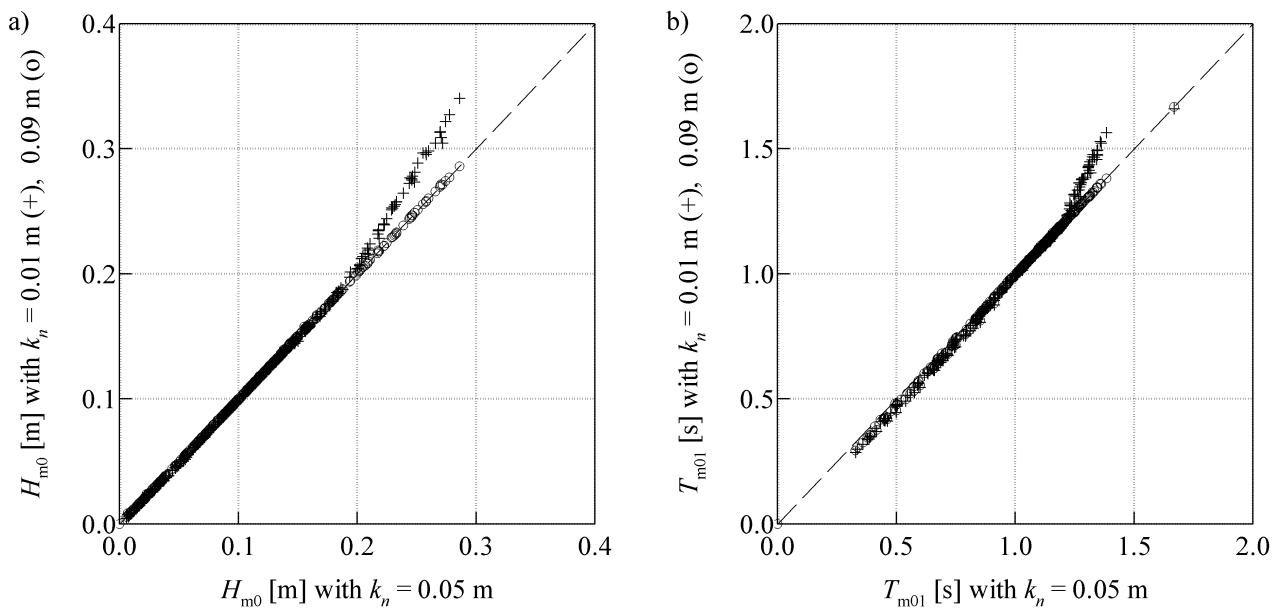

Fig. 7. Scatter diagram of $H_{m 0}$ (a) and $T_{m 01}$ (b) for different $k_{n}$ values. The dashed diagonal represents an exact match

2010).

Boundary conditions in geographical and spectral space are also needed to solve the action balance equation (8). In geographical space the boundaries of the computational grid can be land or water. The land does not generate waves and in SWAN it absorbs all incoming wave energy. In the case of a water boundary the incoming wave components are imposed and the waves can leave the model freely across that boundary. The boundaries in frequency space are fully absorbing at the lowest and the highest discrete frequency. When the directional space is a closed circle, no boundary conditions are needed for any direction.

In case of non-stationary computations the default initial spectra are computed from the local wind velocities using the 
deep-water growth curve of Kahma and Calkoen (1992) [22], cut off at values of the significant wave height and peak frequency from Pierson and Moskowitz (1964) [32]. The initial shape of the spectrum is the classical JONSWAP [16] with a $\cos ^{2}(\theta)$ directional distribution centred around the local wind direction. Using these equilibrium initial conditions renders the effect of the linear term of the wave generation negligible at startup.

\section{Model setup}

All the described source term components were activated in our investigation although not all of them have direct effect on the results at the measurement point. Wave-current interaction was not considered. When setting the spatial resolution of the grid to $100 \mathrm{~m}$, we considered the nonlinearity in the governing equations, the variability of the wind field and the complexity of the lake morphology. We also analysed the effect of discretisation in the frequency space, directional space and for the time. Based on these analyses the 2D spectrum in each geographical point was described in 16 directions, at 42 discrete frequencies between $0.1 \mathrm{~Hz}$ and $5.0 \mathrm{~Hz}$. The applied time step was $0.5 \mathrm{~min}$.

The 2D wave model was built based on the bathymetry survey (Fig. 8) of Bácsatyai et al. (1997) [2]. Only the larger northern part of the lake was incorporated in the model because we considered the interaction with waves in the smaller southern basins negligible. The water level was determined to reproduce the depth at the measurement point.

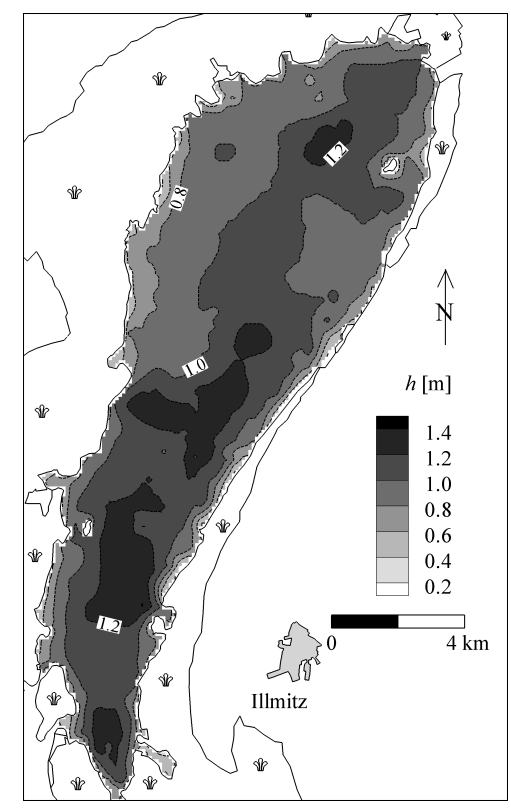

Fig. 8. The distribution of the mean water depth in the northern basin during the two measurement periods

\section{Calibration and validation}

We used the measurements in October for the calibration and the measurements in July for the validation of the model. For the evaluation of the model we compared the measured and modelled wave parameters and spectra as well. For the quantitative evaluation of the model performance the bias parameter, root- mean-square error, scatter index and correlation coefficient have been used:

$$
\begin{array}{r}
\mathrm{BIAS}=\frac{1}{N} \sum_{i=1}^{N}\left(S_{i}-O_{i}\right), \\
\mathrm{RMS}=\sqrt{\frac{1}{N} \sum_{i=1}^{N}\left(S_{i}-O_{i}\right)^{2}} \\
\mathrm{SI}=\frac{\mathrm{RMS}}{\frac{1}{N} \sum_{i=1}^{N} O_{i}} \cdot 100, \\
\mathrm{R}^{2}=\left(\frac{\left.\sum_{i=1}^{N}\left(S_{i}-\bar{S}\right)\left(O_{i}-\bar{O}\right)\right)^{2}}{N \cdot s_{S} \cdot s_{O}}\right)^{2}
\end{array}
$$

with BIAS = bias parameter; RMS = root-mean-square error; $\mathrm{SI}=$ scatter index; $R^{2}=$ correlation coefficient; $N=$ the number of data; $O_{i}=$ the measured value; $S_{i}=$ the predicted value; $\bar{O}_{i}$ and $\bar{S}=$ mean values; $s_{O}$ and $s_{S}=$ standard deviation of the measured and predicted data.

The adopted parameters based on the calibration for the whitecapping are $C_{\mathrm{ds}}^{\prime}=6.5\left(C_{d s}=5.92 \times 10^{-5}\right) ; \delta=1.0 ; p=4$ and for the bottom friction $k_{n}=0.001 \mathrm{~m}$. The scatter plot of the model-data comparison for $H_{m 0}$ is shown for SPM in Fig.9 9 and for SWAN in Fig. 9p.

In October SWAN gives better estimation for $H_{m 0}$ than SPM. The bias of $H_{m 0}$ estimated by SWAN is almost zero but SPM results are rather overestimated. The root-mean-square error of SWAN is smaller than that of SPM although both are in an acceptable range. The correlation coefficient values are rather high and similar to each other showing that the results of both models are well correlated with the measured $H_{m 0}$. The scatter index of SPM is almost the double.

The scatter plot of the model-data comparison for $T_{m 01}$ is shown for SPM in Fig. 10a and for SWAN in Fig. 10p. The SWAN model predicted $T_{m 01}$ more precisely than the SPM formula. The SPM formulas tend to overestimate $T_{m 01}$ while the estimation of SWAN is largely unbiased. All error indicators demonstrate the superiority of the SWAN model, but the results of both models are actually well correlated with the measured $T_{m 01}$.

Two representative wave spectra are shown in Fig. 11. One spectrum was chosen to represents wave states with higher $H_{m 0}$ (Fig. 11 and b) and one spectrum was chosen to represents wave states with lower $H_{m 0}$ (Fig. 11 f and d). Both time instants were chosen to be preceded by more or less constant wind conditions: the average wind speed was $12 \mathrm{~m} / \mathrm{s}$ with $\mathrm{N}-\mathrm{NE}$ direction and $4 \mathrm{~m} / \mathrm{s}$ with $\mathrm{N}$ direction during the preceding hours. Measured wave spectra were smoothed with a $0.16 \mathrm{~Hz}$ wide moving average to be comparable with modelled wave spectra.

Turbulence and measurement errors are present in the whole measured spectrum but they are negligible except at higher frequencies. To reduce errors in the calculated wave parameters 

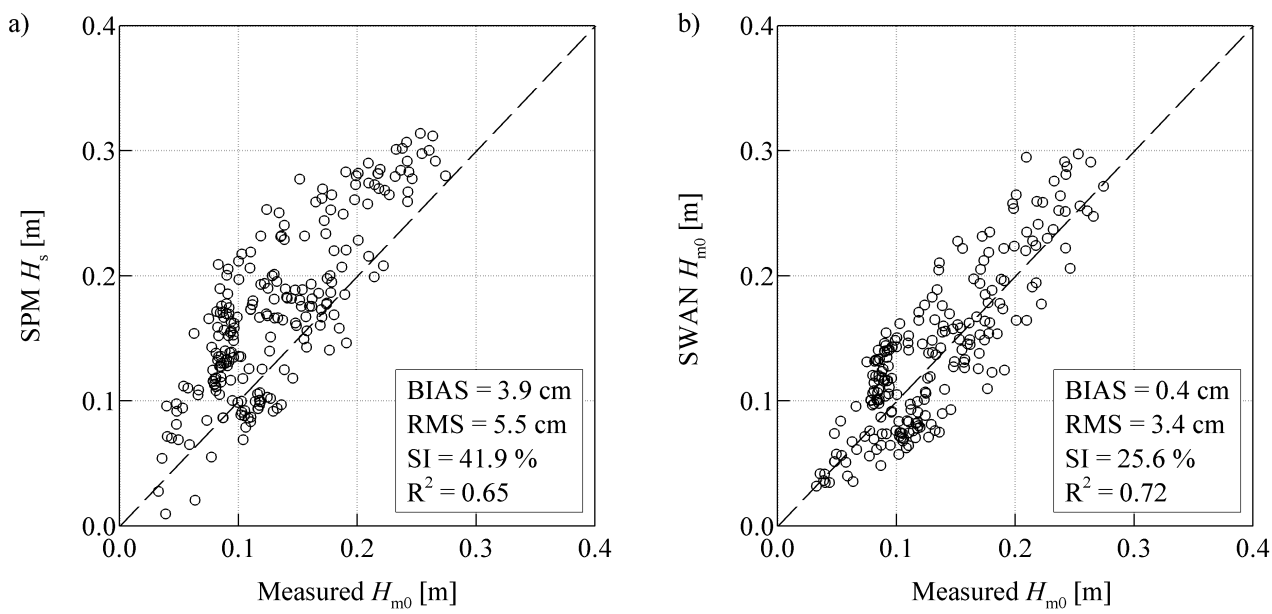

Fig. 9. Scatter diagram of wave height for the calibration period. The dashed diagonal represents an exact match
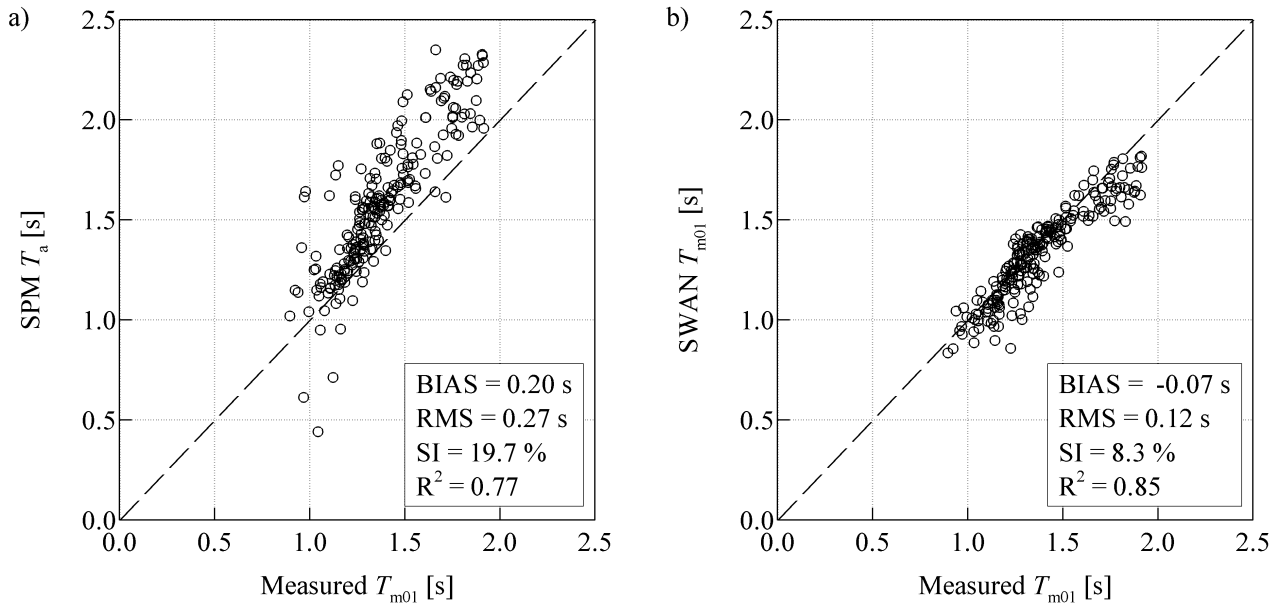

Fig. 10. Scatter diagram of wave period for the calibration period. The dashed diagonal represents an exact match
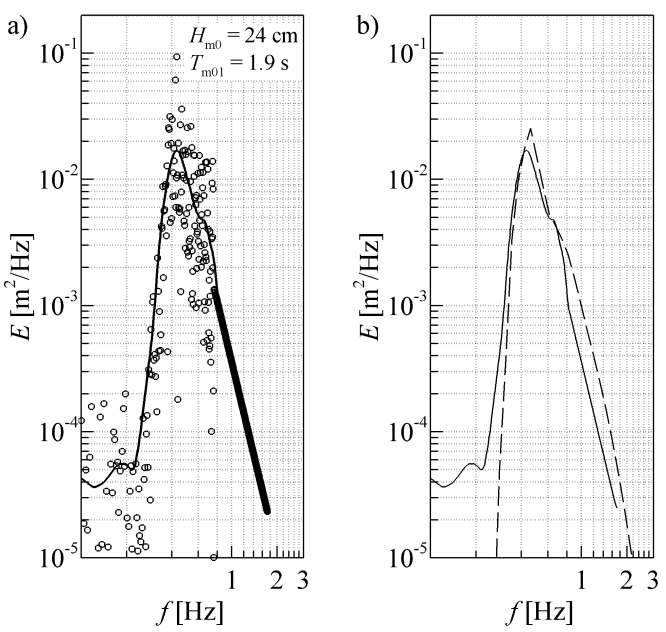

Fig. 11. Raw (circles) as well as filtered (solid line) measured and modelled energy density spectra (dashed line) at 12:00 on 17 October (plots a and b) and

tails of the measured wave spectra were replaced with a power function [18] The shape of the measured and modelled wave spectra is similar, which reflects why the $T_{m 01}$ estimation was found statistically quite good. The higher $H_{m 0}$ values are rather overestimated (Fig. (4)and 9) while the lower $H_{m 0}$ values are underestimated in the first half of the calibration period (Fig.4 and
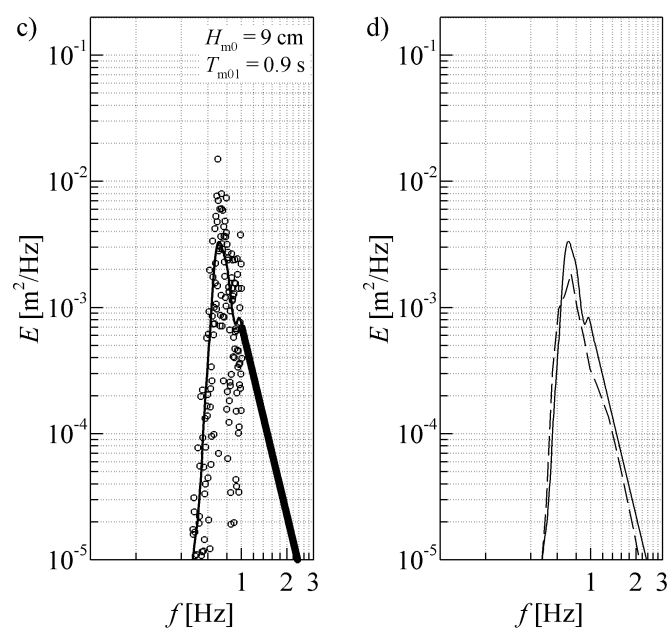

12:00 on 14 October (c and d), 2005

97 and overestimated in the second half of the calibration period. By definition $f_{m 01} \equiv 1 / T_{m 01}$ designates the frequency of the centroid of the wave spectrum; this mean frequency (shown with dots in Fig. 12 is consistently higher than the peak frequency due to the asymmetry of the spectra.

To check the calibration the measurements in July were used 

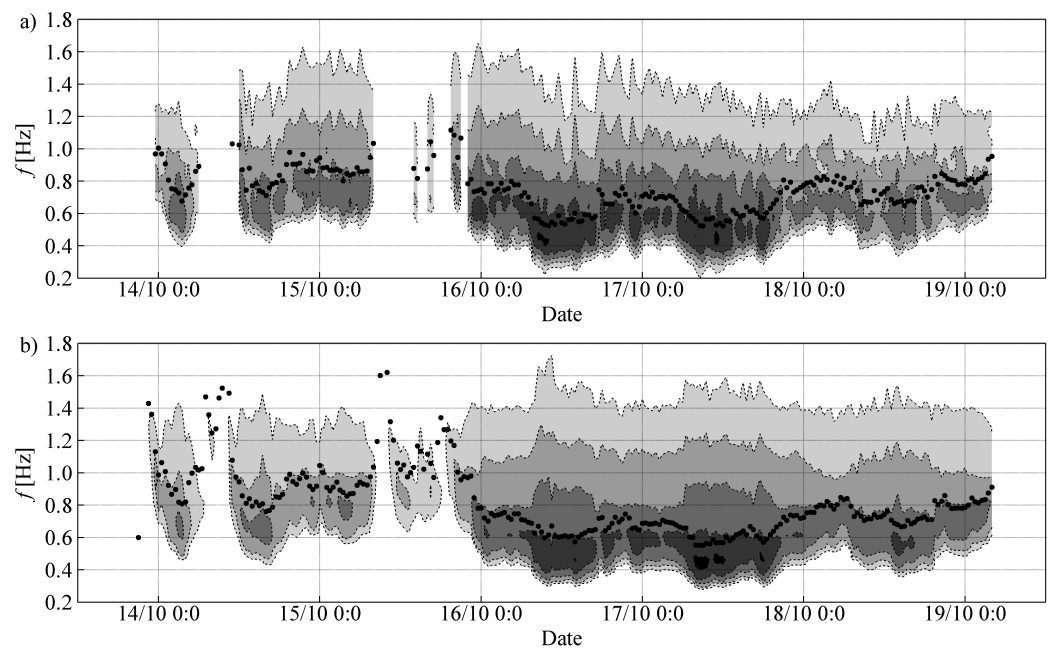

Fig. 12. Time series of the filtered measured (a) and modelled (b) energy density spectra for the same period as in Fig. 4 Contour levels are distributed

for the validation of the SWAN model. The scatter plot of the model-data comparison for $H_{m 0}$ is shown for SPM in Fig. 13 a and for SWAN in Fig. 13 p.

Considering the whole validation period in July, SPM gives a lower RMS error for $H_{m 0}$ than SWAN, but highest $H_{m 0}$ values are estimated more accurately by SWAN. While in October both methods overestimated $H_{m 0}$, in July both underestimate it. The difference is minor between the root-mean-square error and the scatter index of SWAN and SPM. Lastly, the two models are well correlated with the measured $H_{m 0}$, which is in a similar range as in the calibration period.

The scatter plot of the model-data comparison for $T_{m 01}$ is shown for SPM in Fig. 14a and for SWAN in Fig. 14p. The SWAN model predicts $T_{m 01}$ more precisely than the SPM formula, similarly to the calibration period. The SPM formula overestimates $T_{m 01}$ while the estimation of SWAN is unbiased. There are still large differences in the error parameters between SPM and SWAN, but the ratio is $\sim 1.5$ only instead of $\sim 2$ for the calibration dataset.

Neither estimate is especially well correlated with the measured $T_{m 01}$, though the $\mathrm{R}^{2}$ coefficients would improve if more records were classified outliers and were excluded.

Measured and modelled wave spectra (Fig. 15) agree better than in the calibration period. Again, both wave states are preceded with more or less constant wind conditions with NW direction and $12 \mathrm{~m} / \mathrm{s}$ and $6 \mathrm{~m} / \mathrm{s}$ average speed. The magnitude of the modelled spectral energy is smaller than the measured one during the whole validation period (Fig. 3 and 16, causing $H_{m 0}$ to be underestimated during the whole calibration period.

Fig. 17] shows an example of the distribution of the three main wave parameters at 8:30 on 17 October. The wind speed was higher than $10 \mathrm{~m} / \mathrm{s}$ in the preceding two and half hours with an almost N-NW direction. The results are determined by the fetch and water depth conditions in major part of the lake. exponentially from 0.0001 to $0.02 \mathrm{~m}^{2} / \mathrm{Hz}$. Dots represent the mean frequency $f_{m 01}$

\section{Internal boundary layer model}

As described above, the abrupt change of roughness at the land-water and reed-water interface causes fetch-dependent wind speed distribution over the lake even in uniform overland wind conditions. This inhomogeneity can be described by an algebraic IBL model. It was shown that this IBL-based wind variability has significant effect on hydrodynamic processes in shallow lakes and it was taken into account in the hydrodynamic modelling of Lake Neusiedl [25]. The effect of IBL-based wind variability on wave properties was investigated by van Vledder (1999) [35], who concluded that this effect is not significant as it remains in the order of $5 \%$. Those investigations were made in conditions deeper than in Lake Neusiedl. The effect of temperature differences between the air and water were also investigated while in this paper the surface boundary layer was considered neutral. To see if there is also a significant effect of the wind field variability on the wave properties, four model runs were performed in a $1.5 \mathrm{~m}$ deep, $10 \mathrm{~km} \times 10 \mathrm{~km}$ large test basin. The first one ('const10') was made with spatially uniform $10 \mathrm{~m} / \mathrm{s}$ wind speed; the second one ('IBL1') was made with an IBLbased wind speed distribution fitted to $10 \mathrm{~m} / \mathrm{s}$ at the downwind shore; the third one ('IBL2') was made with an IBL-based wind speed distribution fitted to $10 \mathrm{~m} / \mathrm{s}$ at the upwind shore and the fourth one ('const12.65') was made with uniform wind speed equal to the fetch-average of 'IBL2', $w=12.65 \mathrm{~m} / \mathrm{s}$. The last model run was defined to find out if the wave field obtained with an IBL-based wind profile can be reproduced using a uniform wind averaging that analytical profile. The longitudinal profiles of the four wind inputs and the resulting bulk wave parameters are shown in Fig. 18

First of all, at these fetch-limited dimensions the wind speed is seen to depart by as much as $\pm 30 \%$ from its base value of $10 \mathrm{~m} / \mathrm{s}$ according to the IBL theory (Fig. $18 \mathrm{a}$ ). This indicates in advance that the distribution of waves will be affected. Indeed, differences between $H_{m 0}, T_{m 01}$ and $L$ calculated with the various 

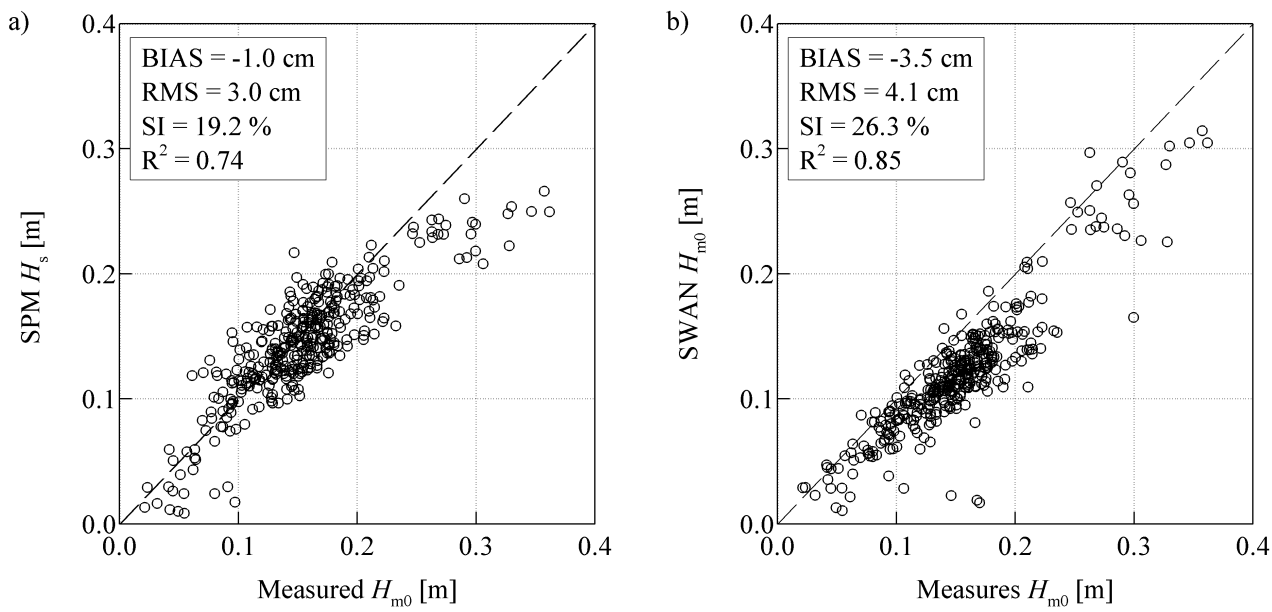

Fig. 13. Scatter diagram of wave height for the validation period. The dashed diagonal represents an exact match
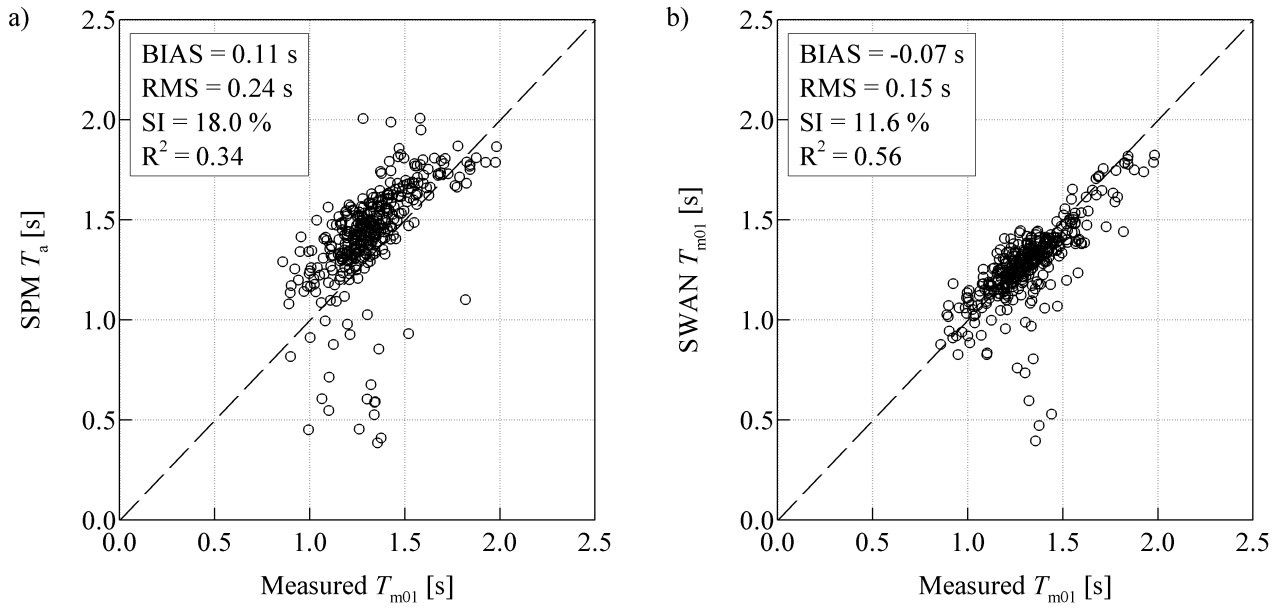

Fig. 14. Scatter diagram of wave period (c-d) for the validation period. The dashed diagonal represents an exact match
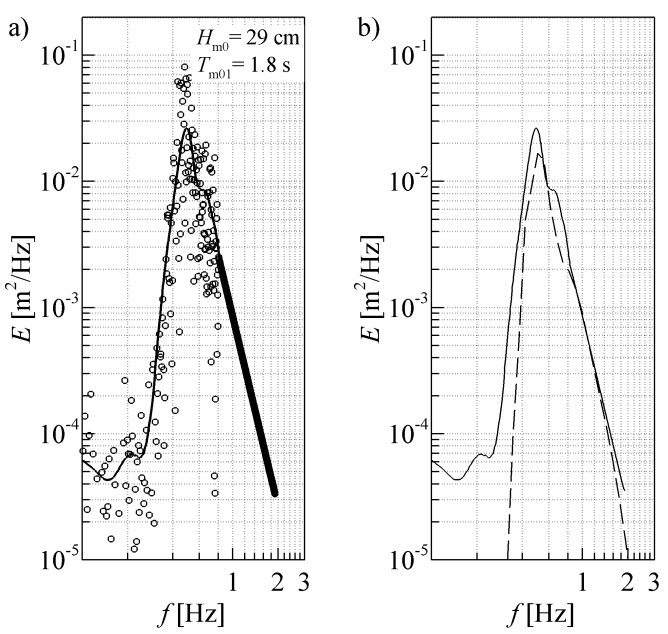

Fig. 15. Raw (circles) as well as filtered (solid line) measured and modelled energy density spectra (dashed line) at 13:48 on 5 July (a-b) and at 15:48 on 8

wind profiles are in the range $10-15 \mathrm{~cm}, 0.7 \mathrm{~s}$ and $1.0-1.5 \mathrm{~m}$, respectively. The SPM formulas (5) and (6) also reflect that $H_{m 0}$ scales with $w^{2}$ and $T_{m 01}$ scales with $w$, roughly. Thus differences in the wind profile are more accentuated for the wave height than for the wave period. Following the same argument, defining the profile 'const12.65' as the arithmetic mean of 'IBL2' succeeds in equating $T_{m 01}$ at longer fetches but not $H_{m 0}$. Instead, a root-
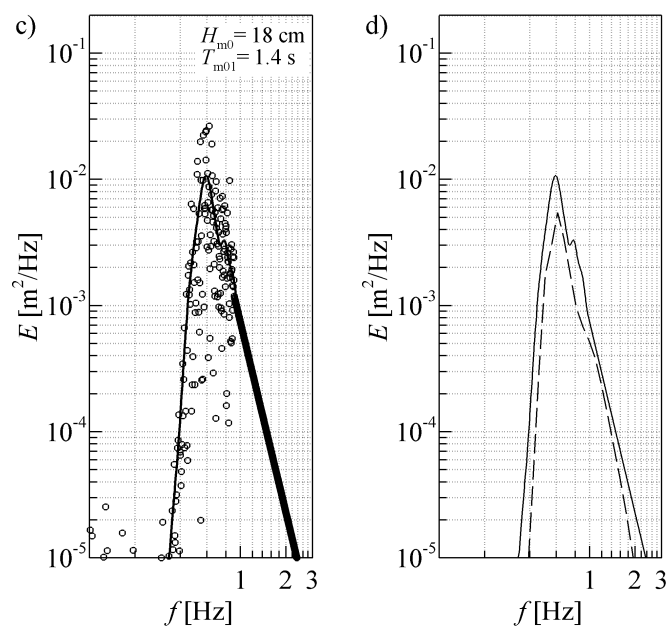

July (c-d), 2005

mean-square averaging would be probably more adequate for the wave height, though we did not analyse averaging methods any further.

In general both the total wind energy input and its local values differ between the model variants and these differences affect waves simultaneously. As the relative difference of the wind is greatest at shorter fetches, the relative difference of bulk wave 

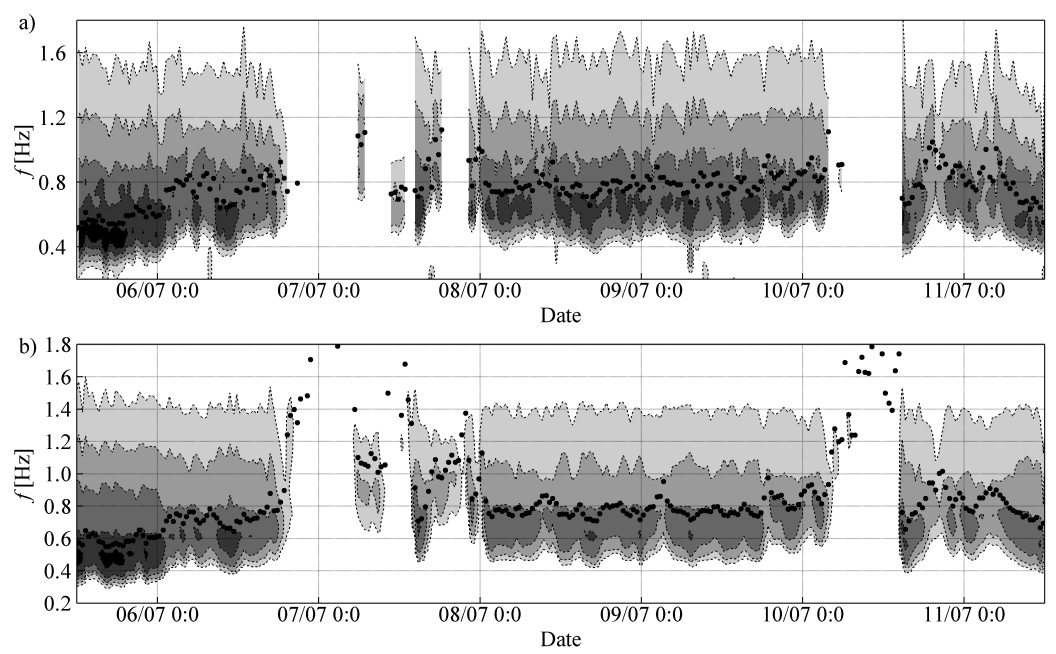

Fig. 16. Time series of the filtered measured (a) and modelled (b) energy exponentially from 0.0001 to $0.02 \mathrm{~m} / \mathrm{Hz}$. Dots represent the mean frequency density spectra for the same period as in Fig. 3 Contour levels are distributed $\quad f_{m 01}$
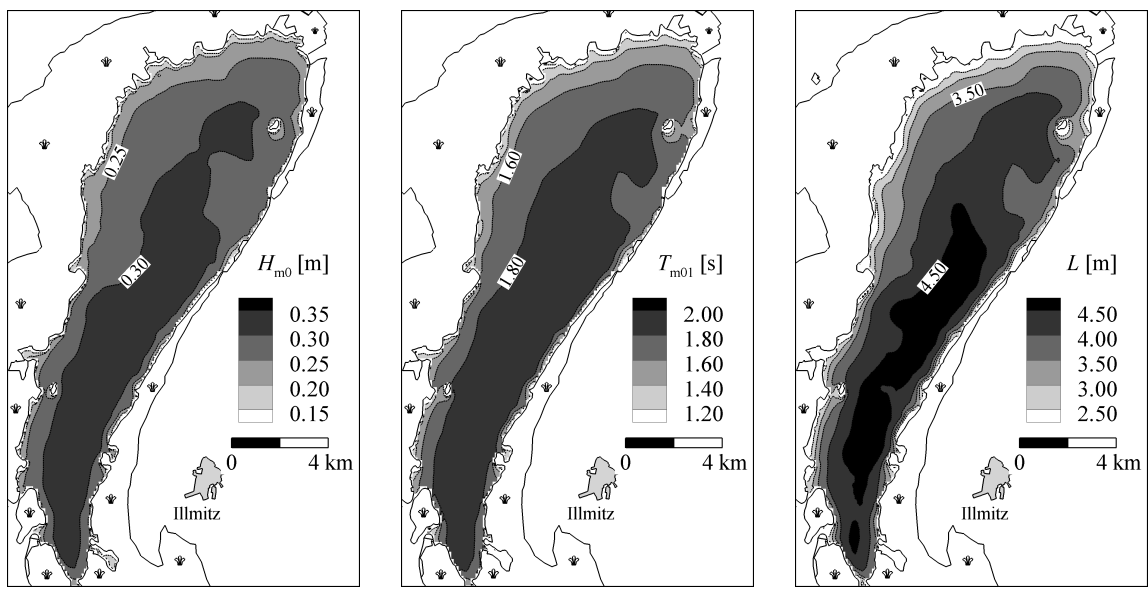

Fig. 17. Modelled wave height, wave period and wavelength distributions at 8:30 on 17 October, 2005
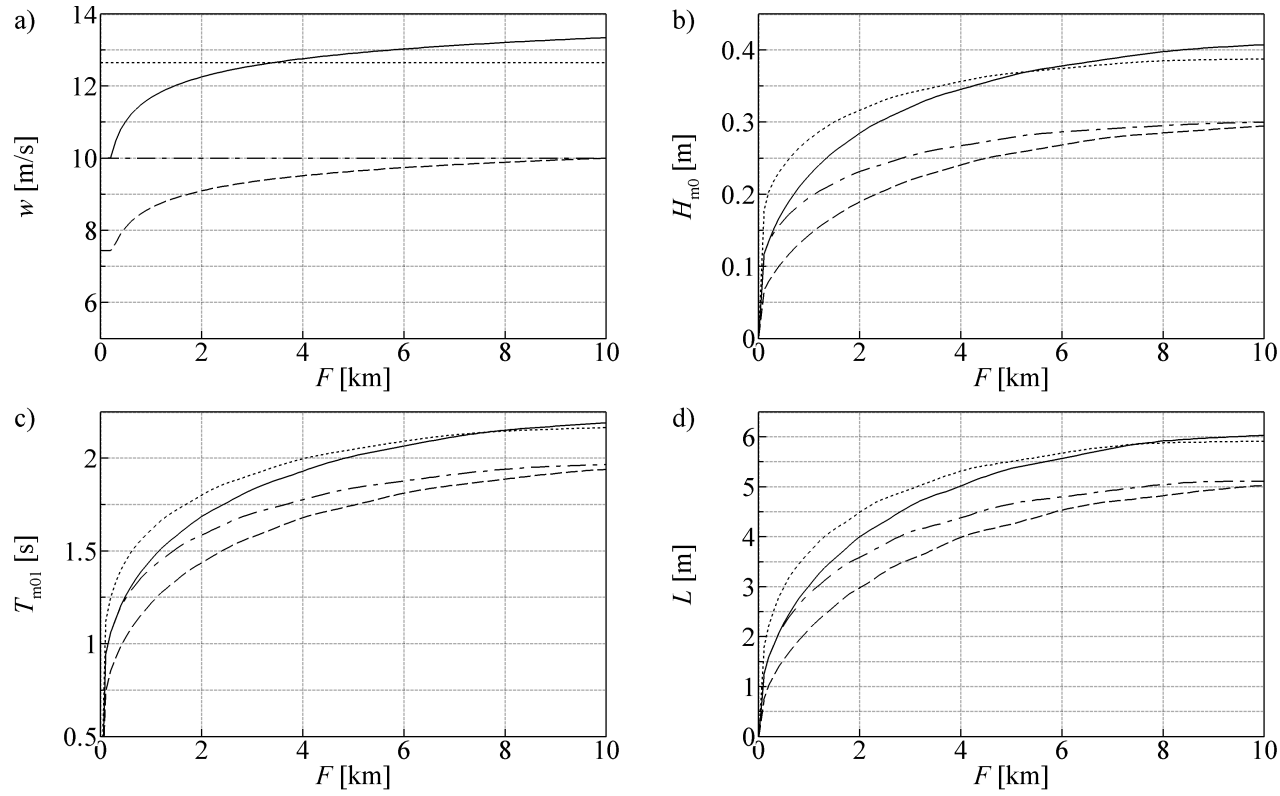

Fig. 18. Profile of $w$ (a), $H_{m 0}$ (b), $T_{m 01}$ (c) and $L$ (d) along the wind-aligned centreline of the test basin. The line types denote the different wind profile

parameters is also greatest near the upwind shore. Wave parameters estimated by simulations 'const10' and 'IBL1' converge

assumptions: 'const10' - dash-dotted line, 'IBL1' - dashed line, 'IBL2' - solid line and 'const12.65' - dotted line

to the same value at long fetches. Similarly to van Vledder's results, the absolute difference in $H_{m 0}$ between 'const10' and 
'IBL2' winds is $10 \mathrm{~cm}$ at the highest fetches, which is significant relative to the $25-40 \mathrm{~cm}$ magnitude of $H_{m 0}$. The differences in $T_{m 01}$ and $L$ at the same place are also significant (10 and $15 \%$ respectively).

As it is known, in shallow water the oscillatory wave motion generates significant shear and turbulence at the bed, which interacts with the shear due to large-scale horizontal motions. This interaction has a dominant role in sediment transport because the resultant oscillating shear stress determines the erosion, deposition and the horizontal entrainment of sediment particles. Here we estimate the wave-induced shear stress based on the model of Grant and Madsen (1979) [12] with zero mean current velocity:

$$
\tau_{\mathrm{wm}}=\frac{1}{2} f_{\mathrm{cw}} \rho u_{\mathrm{bm}}^{2}
$$

with $\tau_{\mathrm{wm}}=$ the maximum wave-induced shear stress during a wave period; $u_{b m}=$ maximum bottom orbital velocity calculated by linear wave theory; $\rho=$ water density and $f_{c w}=$ a DarcyWeisbach friction coefficient. To calculate $f_{c w}$, we must iteratively solve

$$
\frac{1}{4 \sqrt{f_{\mathrm{cw}}}}+\log _{10} \frac{1}{4 \sqrt{f_{\mathrm{cw}}}}=\log _{10} \frac{A_{\mathrm{bm}}}{k_{n}}-0.17
$$

for fully rough turbulent conditions $\left(\operatorname{Re}_{r}>3.3\right)$, and

$$
\frac{1}{4 \sqrt{4 f_{\mathrm{cw}}}}+\log _{10} \frac{1}{4 \sqrt{4 f_{\mathrm{cw}}}}=\log _{10} \sqrt{\frac{R e_{\mathrm{w}}}{50}}-0.17
$$

for smooth turbulent conditions $\left(\operatorname{Re}_{r} \leq 3.3\right)$ where $A_{\mathrm{bm}}=$ bottom excursion amplitude; $k_{n}=$ equivalent Nikuradze sand-grain roughness; $R e_{w}$ and $R_{e} r=$ wave and boundary Reynolds number, respectively:

$$
R e_{w}=\frac{A_{\mathrm{bm}} u_{\mathrm{bm}}}{v}, \quad R e_{r}=\frac{k_{n} u_{* \mathrm{wm}}}{v}
$$

where $u_{* \mathrm{wm}}=$ the maximum wave-induced shear velocity during a wave period; $v=$ kinematic viscosity of water. In our investigations $k_{n}=1 \mathrm{~mm}$ was used. The longitudinal profile of the bottom shear stress calculated in such a way in the test basin is shown in Fig. 19

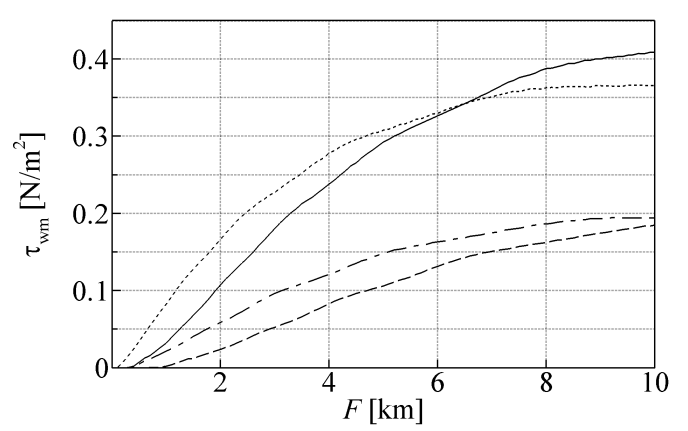

Fig. 19. Wave-induced bottom shear stress profile along the centreline of the test basin. As before, the line types denote the different wind profile assumptions: 'const10' - dash-dotted line, 'IBL1' - dashed line, 'IBL2' - solid line and 'const12.65' - dotted line

Comparing to the wave properties studied earlier, the differences are higher in $\tau_{\mathrm{wm}}$ and not obvious. The ratio of $H_{m 0}$ calculated with winds 'IBL2' and 'const10' is $\sim 1.3$ but the ratio of $\tau_{\mathrm{wm}}$ is $\sim 2.1$. The $\tau_{\mathrm{wm}}$ calculated by simulation 'IBL2' and 'const12.65' are closer to each other, but the difference is significant. Although the $\tau_{\mathrm{wm}}$ calculated by winds 'const10' and 'IBL1' converge to the same value at high fetches, there is significant difference between them almost along the whole profile.

To see if there is some effect on the results when the wind is not parallel to either side of the basin, three of the previous investigations were repeated with an oblique N-NW wind direction in a $1.5 \mathrm{~m}$ deep, $5 \mathrm{~km} \times 10 \mathrm{~km}$ large basin. The distribution of the fetch averaged on a $24^{\circ}$ wide fan around the wind direction and the IBL-based wind speed over the test basin are shown in Fig. 20
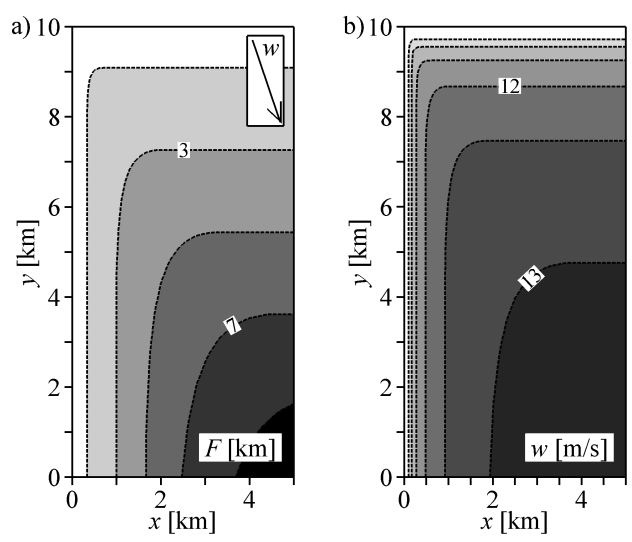

Fig. 20. Distribution of fetch (a) and IBL-based wind speed (b) over the test basin. Wind direction is NNW as shown in plot a

$H_{m 0}$ and $\tau_{\mathrm{wm}}$ results are shown in Fig. 21,23. The conclusions are more or less similar to the ones of the previous investigation done with shore-aligned wind. The difference between results with uniform $10 \mathrm{~m} / \mathrm{s}$ wind speed and the IBL-based wind speed fitted to $10 \mathrm{~m} / \mathrm{s}$ at the upwind shore is the highest at the long fetches. The longer the fetch, the larger the difference (Fig. 22-d). The highest magnitude of the difference of $H_{m 0}$, $T_{m 01}, L$ and $\tau_{\mathrm{wm}}$ is about $0.10 \mathrm{~m}, 0.15 \mathrm{~s}, 0.7 \mathrm{~m}$ and $0.15 \mathrm{~N} / \mathrm{m}^{2}$, respectively, i.e., all proved significant.

This time the area-average of the IBL-based wind speed over the lake yielded a different value as in the case of coordinate aligned wind. This $12.4 \mathrm{~m} / \mathrm{s}$ uniform wind speed produced higher $H_{m 0}$ along the upwind shore (Fig. 23r) and higher $\tau_{\mathrm{wm}}$ in the offshore areas (Fig. 23d).

\section{Summary and conclusions}

In the first part of this paper the validity of a $2 \mathrm{D}$ numerical wave model in very shallow water was shown. The 2D spectral wave model SWAN was implemented for the northern basin of Lake Neusiedl whose average depth is about 1.0-1.5 m and waves are locally generated. As a result of the calibration the model was able to reproduce the measured wave properties with acceptably small error. For example the root-mean-square error of the wave height $H_{m 0}$ was only $3-5 \mathrm{~cm}$, the RMS error of the wave period $T_{m 01}$ was only $0.1-0.15 \mathrm{~s}$. The measured and the modelled wave spectra are in general well correlated. 

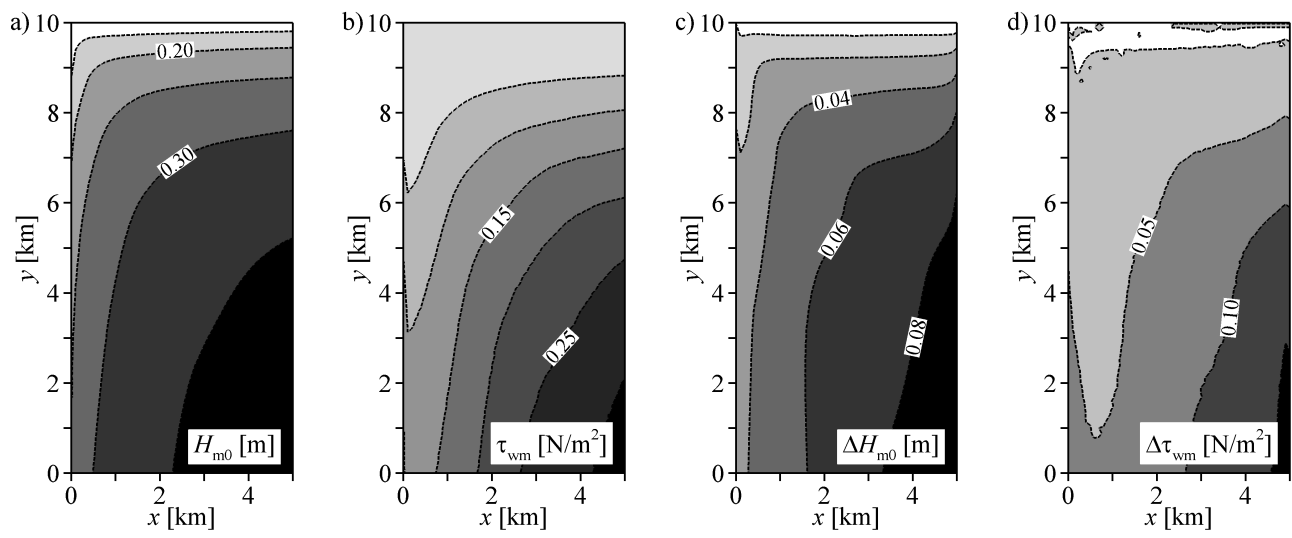

Fig. 22. $H_{m 0}$ (a) and $\tau_{w m}$ (b) distribution for IBL-based wind speed fitted to $10 \mathrm{~m} / \mathrm{s}$ at the upwind shore and differences from the uniform wind speeds in
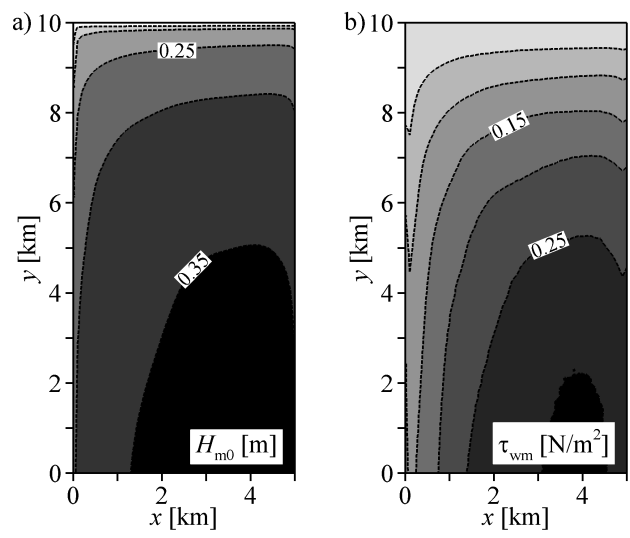

Fig. 23. $H_{m 0}$ (a) and $\tau_{w m}$ (b) distribution for uniform wind speed ( $w=12.40 \mathrm{~m} / \mathrm{s}$, average of the IBL-based distribution) and differences from
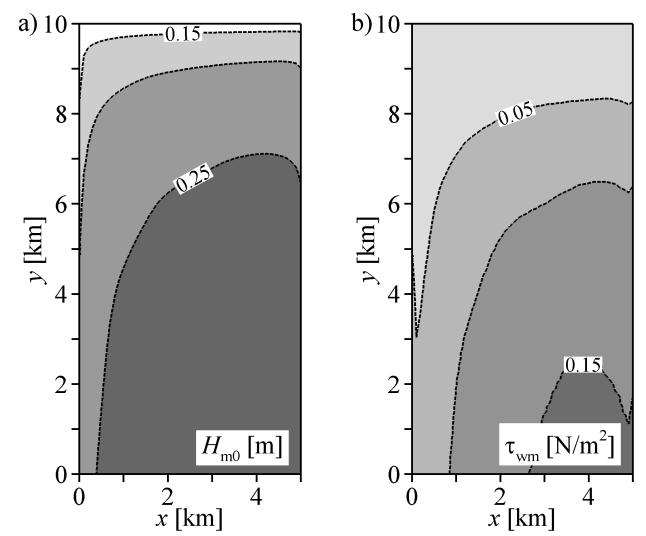

Fig. 21. $H_{m 0}$ (a) and $\tau_{w m}$ (b) distribution for uniform wind speed, $w=10 \mathrm{~m} / \mathrm{s}$

As expected, it was shown that the numerical model matches the measured $T_{m 01}$ more closely that the simple, analytical estimates of SPM. On the other hand, the RMS error of $H_{m 0}$ is rather similar in both models, less than $1.5 \mathrm{~cm}$, i.e., the numerical model did not reduce the error of the SPM formula in spite of parameter calibration and the much greater computational cost. However, the more relevant higher $H_{m 0}$ values are predicted more accurately by the numerical model, benefiting the determination of design wave loads or exceedance of bed shear stresses for erosion.

In the second part of this paper the effect of a more realis-

Fig.21.c-d)
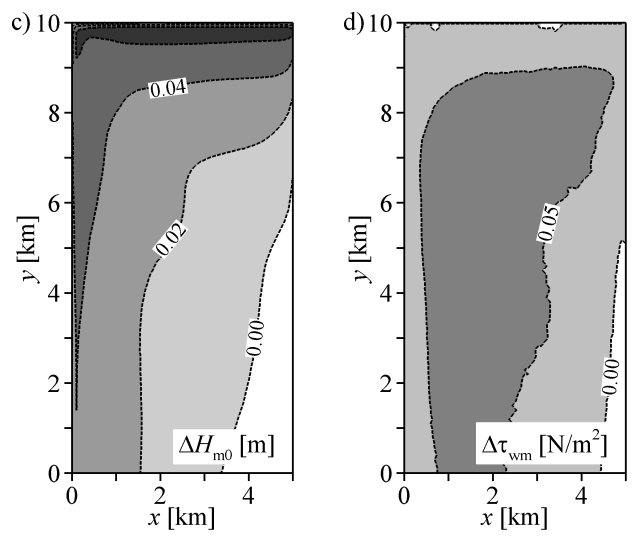

the IBL-based wind speeds in Fig. 22 (c-d)

tic, spatially varying wind speed distribution on the modelled wave properties was investigated. The spatial inhomogeneity in the wind speed is a consequence of the variability of the surface roughness, reasonably well approximated in fetch-limited conditions by the theory of internal atmospheric boundary layers.

It was shown that all this has a significant, fetch-dependent effect on wind and wave parameters, furthermore, this effect is accentuated when transformed to wave-related bed stresses. In conclusion, in fetch-limited lakes it is potentially wrong to force a wave model uniformly with wind data directly measured overland or onshore, regardless of whether it is on the upwind or downwind shore. We therefore advocate the use of micrometeorological models for distributing the wind shear stress, and the inclusion of offshore wind stations in field campaigns. At larger horizontal scales, say above $20 \mathrm{~km}$, meso- and synoptic scale variations become important and atmospheric circulation models are needed to properly account for the variability of the wind input in wave models.

\section{Acknowledgements}

The work reported in the paper has been developed in the framework of the project "Talent care and cultivation in the scientific workshops of BME" project. This project is supported by the grant TÁMOP-4.2.2.B-10/1-2010-0009. The work of T. Krámer was also supported by the Bolyai János Research Grant of the Hungarian Academy of Sciences. 


\section{References}

1 Alari V, Raudsepp U, Kõuts T, Wind wave measurements and modelling in Kündema Bay, Estonian Archipelago Sea, Journal of Marine Systems 74 (2008), S30-S40, DOI 10.1016/j.jmarsys.2007.11.014.

2 Bácsatyai L, Csaplovics E, Márkus I, Sindhuber A, Digitale Geländemodelle des Neusiedler See-Beckens, Burgenländisches Landesmuseum, Eisenstadt, Österreich, 1997.

3 Baranya S, Józsa J, Numerical and laboratory investigation of the hydrodynamic complexity of a river confluence, Periodica Polytechnica, Civil Enginnering 51 (2007), no. 1, 3-8, DOI 10.3311/pp.ci.2007-1.01.

4 Battjes J. A, Janssen J. P. F. M, Energy loss and set-up due to breaking of random waves, 16th International Conference on Coastal Engineering (Hamburg, Germany, August 1978), Proceedings of Sixteenth Coastal Engineering Conference, American Society of Civil Engineers, 1978, pp. 569587.

5 Booij N, Ris R. C, Holthuijsen L. H, A third-generation wave model for coastal regions. 1. Model description and validation, Journal of Geophysical Research 104 (1999), no. C4, 7649-7666, DOI 10.1029/98JC02622.

6 Cavaleri L, Rizzoli P. M, Wind wave prediction in shallow water: Theory and applications, Journal of Geophysical Research 86 (1981), no. C11, 10961-10973, DOI 10.1029/JC086iC11p10961.

7 Shore Protection Manual, 4th ed., US Army Corps of Engineers, Coastal Engineering Research Center, 1984.

8 Collins J. I, Prediction of shallow water spectra, Journal of Geophysical Research 77 (1972), no. 15, 2693-2707.

9 Eldeberky $\mathbf{Y}$, Nonlinear transformation of wave spectra in the nearshore zone, $\mathrm{PhD}$ thesis, Delft University of Technology, Delft, The Netherlands, 1996.

10 Eldeberky Y, Battjes J. A, Parameterization of triad interaction in wave energy models, International Conference on Coastal Research in Terms of Large Scale Experiments (Gdansk, Poland, September 4-8, 1995), Coastal Dynamics '95, American Society of Civil Engineers, 1996, pp. 140-148.

11 Eldeberky Y, Battjes J. A, Spectral modelling of wave breaking: Application to Boussinesq equations, Journal of Geophysical Research 101 (1996), no. C1, 1253-1264, DOI 10.1029/95JC03219.

12 Grant W D, Madsen O S, Combined wave and current interaction with a rough bottom, Journal of Geophysical Research 84 (1979), no. C4, 17971808, DOI 10.1029/JC084iC04p01797.

13 Günther H, Hasselmann S, Janssen P. A. E. M, The WAM model Cycle 4 (revised version), Deutsche Klimarechenzentrum, Hamburg, Germany, 1992.

14 Hasselmann K, On the spectral dissipation of ocean waves due to whitecapping, Boundary-Layer Meteorology 6 (1974), no. 1-2, 107-127.

15 Hasselmann K, Barnett T. P, Bouws E, Carlson H, Cartwright D. E, Enke K, Weing J. A, Gienapp H, Hasselmann D. E, Kruseman P, Meerburg A, Muller P, Olbers K. J, Richter K, Sell W, Walden W. H, Measurements of wind-wave growth and swell decay during the Joint North Sea Wave Project (JONSWAP), Deutsches Hydrographisches Institut, 1973.

16 Hasselmann S, Hasselmann K, Allender J. H, Barnett T. P, Computations and parameterizations of the nonlinear energy transfer in a gravity wave spectrum, Part II: Parameterizations of the nonlinear transfer for application in wave models, Journal of Physical Oceanography 15 (1985), no. 11, 1378-1391.

17 Hill M. C, Methods and guidelines for effective model calibration, U.S. Geological Survey, Denver, Colorado, USA, 1998.

18 Homoródi K, Józsa J, Krámer T, Ciraolo G, Nasello C, Identifying wave and turbulence components in wind-driven shallow basins, $\mathrm{Pe}$ riodica Polytechnica, Civil Enginnering 56 (2012), no. 1, 87-95, DOI 10.3311/pp.ci.2012-1.10.

19 Janssen P A E., Quasi-linear theory of wind-wave generation applied to wave forecasting, Journal of Physical Oceanography 21 (1991), no. 11, 16311642, DOI 10.1175/1520-0485(1991)021<1631:QLTOWW>2.0.CO;2.
20 Jin K-R, Ji Z-G, Calibration and verification of a spectral wind-wave model for Lake Okeechobee, Ocean Engineering 28 (2001), no. 5, 571-584, DOI 10.1016/S0029-8018(00)00009-3.

21 Józsa J, Milici B, Napoli E, Numerical simulation of internal boundarylayer development and comparison with atmospheric data, Boundary-Layer Meteorology 123 (2007), 159-175, DOI 10.1007/s10546-006-9134-9.

22 Kahma K K, Calkoen $\mathbf{C} \mathbf{J}$, Reconciling discrepancies in the observed growth of wind-generated waves, Journal of Physical Oceanography 22 (1992), no. 12, 1389-1405, DOI 10.1175/15200485(1992)022<1389:RDITOG>2.0.CO;2.

23 Komen G. J, Cavaleri L, Donelan M, Hasselmann K, Hasselmann S, Janssen P. A. E. M, Dynamics and Modelling of Ocean Waves, Cambridge University Press, 1994.

24 Komen G J, Hasselmann S, Hasselmann K, On the existence of a fully developed wind sea spectrum, Journal of Physical Oceanography 14 (1984), no. 8, 1271-1285, DOI 10.1175/15200485(1984)014<1271:OTEOAF>2.0.CO;2.

25 Krámer T, Józsa J, An adaptively refined, finite-volume model of windinduced currents in Lake Neusiedl, Periodica Polytechnica, Civil Enginnering 49 (2005), no. 2, 111-136.

26 Krámer T, Peltoniemi H, Wave measurement analysis, Budapest University of Technology and Economics, Budapest, Hungary, 2006.

27 Lin W, Sanford L P, Suttles S E, Wave measurement and modelling in Chesapeake Bay, Continental Shelf Research 22 (2002), no. 18-19, 26732686, DOI 10.1016/S0278-4343(02)00120-6.

28 Madsen O S, Poon Y K, Graber H C, Spectral wave attenuation by bottom friction: Theory, 21st International Conference of Coastal Engineering (Coata del Sol-Malaga, Spain, June 20-25, 1988), Coastal Engineering (1988), American Society of Civil Engineers, 1989, pp. 492-504.

29 Miles $\mathbf{J}$ W, On the generation of surface waves by shear flows, Journal of Fluid Mechanics 3 (1957), no. 2, 185-204, DOI 10.1017/S0022112057000567.

30 Moeini M H, Etemad-Shahidi A, Wave parameters hindcasting in a lake using SWAN model, Iranica Scientia 16 (2009), no. 2, 156-164.

31 Phillips $\mathbf{O}$ M, On the generation of waves by turbulent wind, Journal of Fluid Mechanics 2 (1957), no. 5, 417-445, DOI 10.1017/S0022112057000233.

32 Pierson W. J, Moskowitz L, A proposed spectral form for fully developed wind seas based on the similarity theory of S.A. Kitaigorodskii, Journal of Geophysical Research 69 (1964), no. 24, 5181-5190, DOI 10.1029/JZ069i024p05181.

33 Ris R C, Holthuijsen L H, Booij N, A third-generation wave model for coastal regions. 2. Verification, Journal of Geophysical Research 104 (1999), no. C4, 7667-7681, DOI 10.1029/1998JC900123.

34 SWAN team, SWAN - Scientific and technical documentation, Cycle III version 40.81, Delft University of Technology, Delft, The Netherlands, 2010.

35 van Vledder G, Source term investigation, SWAN, Alkyon Hydraulic Consultancy and Research, 1999.

36 The WAMDI Group, The WAM model - a third generation ocean wave prediction model, Journal of Physical Oceanography 18 (1988), no. 12, 17751810.

37 Guide to wave analysis and forecasting, World Meteorological Organization, Geneva, Switzerland, 1998.

$38 \mathrm{Wu} \mathbf{J}$, Wind-stress coefficients over sea surface from breeze to hurricane, Journal of Geophysical Research 87 (1982), no. C12, 9704-9706, DOI 10.1029/JC087iC12p09704. 